\title{
Local Hazard Mitigation Plan (LHMP) is Properly Working?: Evaluation for the LHMP of Kumamoto City
}

\author{
Kim, Hwayoung* and Kakimoto, Ryuji**
}

\begin{abstract}
A local hazard mitigation plan (LHMP) or emergency plan is one of the most effective contributions for the mitigation of future local natural disasters. Since different regions are vulnerable to different natural disasters, each community should prepare their own plan based on their specific conditions. In Kumamoto, chronic flood damage and landslides are the most common hazards. In 2012, rapid heavy rain resulted in substantial property damage, casualties, and even fatalities. Therefore, this paper presents the comparison research for Kumamoto hazard mitigation planning around 10- year time series, a longitudinal study. We used a flood mitigation plan coding protocol to better understand the Kumamoto City hazard mitigation plan. Indicators used in the study mostly focus on situations that the city has recently faced. Ultimately, the purpose of this research is twofold: 1) to assess the current mitigation efforts for a local flood event through a comparison study, and 2) to improve the LHMP more practically. Eventually, through this study, it should be possible to enable the local government of Kumamoto to help establish a community resilient to its chronic natural disasters. Specific goals include determining which parts in the LHMP should be reinforced and whether improving the community resilience to flooding is possible.
\end{abstract}

Key words : Local Hazard Mitigation Plan (LHMP), flood mitigation, and resilient community

\section{요지}

지역방재계획 또는 비상계획은 불확실한 지역자연재해저감을 위한 가장 효과적인 수단중의 하나이다. 지역마다 취약한 자연재해가 다 르기 때문에, 각각의 지역은 그들의 특성에 맞게 방재계획을 준비해야만한다. 쿠마모토에서는 만성적 홍수피해와 산사태가 주된 자연 재해이다. 지난 2012년, 짧은 시간에 쏟아진 폭우로 인해 많은 사상자와 재산상 피해를 입었다. 그래서, 이 연구는 10년의 시간주기로 쿠마모토시의 지역방재계획서를 비교 검토하였다. 본 연구에는 현재의 방재계획서의 역량을 이해하기 위해 플랜코딩 프로토콜이 사용 되었으며, 본 연구에 사용된 지표들은 최근 쿠마모토시가 맞닥들인 취약점을 밝히기 위한 것들 위주로 구성되었다. 궁극적으로, 우리는 이 연구를 통해서 다음과 같은 두가지를 얻으려한다. 첫째, 현재와 과거의 비교연구를 통한 현재의 재해저감노력. 둘째, 그 결과를 토대 로한 실질적 지역방재계획서의 질 향상. 결과적으로, 지역정부는 현재의 취약점을 파악함으로서 실질적인 계획의 향상을 통해 지역의 만성적 자연재해에 대한 회복 탄력성을 키울 수 있을 것이다.

핵심용어 : 지역방재계획, 홍수저감, 회복 탄력성이 있는 지역 사회

\section{Introduction}

In July 2012, Kumamoto city was hit by a rapid flood resulting from heavy raining during the early morning. Many citizens who have been living near the Shirakawa River were being affected. The city suffered substantial property damage and casualties. According to the inspection report by the Japan Society of Civil Engineering, Western Branch in Kyushu, there were 23 fatalities, 2 people missing and 209 completely and 1262 half-destroyed houses. The total damage cost around Mt.
Aso was around 62.1 billion JPY. The Shirakawa River, originates Mt. Aso, goes through Kumamoto city. The city built many structures to protect private facilities and citizens. However, it is turned out from the event in 2012 that those structure methods would not be an adequate way to decrease the damage from a rapid flooding in an urbanized area. Specifically, most casualties and fatalities were occurred along the riverine and rapid cliffs of Mt. Aso, to which many structure measurements have been applied such as channelization, levee, and support. Now, it is the time to find out the compromise between

\footnotetext{
* Corresponding Author. Member. Ph.D Candidate, Graduate School of Science and Technology, Kumamoto University

(Tel: +81-96-342-3513, Fax: +81-96-342-3510, E-mail: eagloo16@gmail.com)

**Professor, Graduate School of Science and Technology, Kumamoto University
} 
non-structure and structure measurement for repetitive floods in the city. To do that, it is necessary that current natural hazard mitigation plan should be assessed whether or not where a gap exists between two measurements. Furthermore, there have been many researches for community-level risk perception (Amao et al., 2007; Yamazaki et al., 2008), the level of community capability for potential disasters (Matsuda and Okada, 2006), community level of flood risk communication (Yamada et al., 2011), and even citizen participation improvement strategies (Okada, 2013a; Okada, 2013b). However, there was little research for administrative level of research to mitigate local hazards. Apparently, it is strongly believed that a Local Hazard Mitigation Plan (LHMP) is the first strong commitment to protect citizens' lives and properties and, of course, make a resilient community. Therefore, it will be the initial step that the plan evaluation for flood mitigation at a study area. In the previous research, we has tried to develop indicators of plan evaluation for the Japan society based on the North-Americans' researches. In this research, it will be tested and applied to the LHMP of Kumamoto City to understand the degree to which LHMP of Kumamoto city associated with flood hazard between 2001 and 2012. Based on the result of assessment of LHMP by using the equation introduced previous contribution, it will be quantified about current Kumamoto City's LHMP so that the scholars would recommend this result to the local public officials and the localite to improve LHMP and let the people know what Kumamoto city need more to be resilient to live along the river. Finally, it will be presented about recommendations to the elected official, the public and further research.

\section{Indicators in Plan Components}

Generally speaking, the regional hazard prevention plan in Japan has included large and various amount of information from disaster preparedness to reconstruction \& revitalization. Unfortunately, it seems to focus more on post-disaster recovery and reconstruction. However, proactive actions such as preparedness, mitigation efforts should be preceded prior to postdisaster efforts. Accordingly, it is definitely to be investigated that the huge amount of information is properly working on local hazard mitigation purpose. In addition, the above efforts should focus more on pre-disaster so that the local government could prevent, at least, mitigate its repetitive loss of life and property in advance. As the first step, we did apply for plan evaluation indicators on Kumamoto City Regional Hazard Prevention Plan (KCRHPP). As mentioned, mitigation plans are large amount of information, mostly context. It does need to be quantified for easy to understand and be compared. Therefore, it is indicators that play important roles in properly evaluating a LHMP. Indicators should include diverse components such as social, economic, and even future development growth pattern in a community. Even if these indicators are not perfect to Japanese culture, it is worthy to better know the status of Kumamoto city's effort to mitigate pre and post disaster loss. In order to propose better plan to a local community, we decided to scrutinize the KCRHPP as a study area. The indicators used to assess the plans are shown in Table 1.

The below indicators in Table 1 will be used to evaluate KCRHPP of 2001 and one of the year of 2012 so that the plan quality of each year can be easily compared with each other. It is very important that the three categories assess a local plan quality. Given that there would be more indicators to evaluate plan quality, it could be more precise. However, many indicators are overlapped in other plans such as general plan, or comprehensive plan. Therefore, indicators used in this research focus only on the followings; socio-economic status (SES), local government commitment to mitigate potential hazards, and monitoring system to mitigate or minimize local natural

Table 1. Evaluating indicators used under each plan component

\begin{tabular}{l|l|l}
\hline \multicolumn{1}{c|}{ Fact } & \multicolumn{1}{c}{ Goal } & \multicolumn{1}{c}{ Implementation/action } \\
\hline 1. Population/population growth & $\begin{array}{l}\text { 1. Efforts to discourage development activity } \\
\text { within local hazardous areas }\end{array}$ & 1. Proper check-up system (monitoring) \\
\hline 2. Children, elders and disable & 2. Efforts of property protection & 2. Precise time-schedule for implementation \\
\hline 3. Single head of household & 3. Efforts to natural resource & $\begin{array}{l}\text { 3. Coordinating with local gov. and localites } \\
\text { (Citizen Participation level) }\end{array}$ \\
\hline 4. No. of local critical facilities & 4. Effort to local fiscal loss & \\
\hline 5. No. of private structures & 5. Efforts to promote sustainable community & \\
\hline 6. Median household income & 6. Effort to public institution facility & \\
\hline 7. Households below poverty & 7. Effort to local awareness promoting & \\
\hline 8. Emergency plan and shelter & $\begin{array}{l}\text { 8. Effort to improve communication and } \\
\text { coordination }\end{array}$ & \\
\hline
\end{tabular}


hazards and damages before potential events occur. Specifically, SES would be one of the important indicators in this research. Due to the fact that Japan has been composed of many mountainous areas, which means taking more time to evacuate and increasing possibilities of flash flood in downstream areas, and the elderly gets increasing in those areas, it should be checked if the plan cope with the dependents (the elderly, children, the disable) well.

\section{Literature Review}

From the last several decades ago, there have been tremendous efforts to improve implementations and application for natural hazards. Mostly, it has been focused on structural implementations such as channelization, levee, seawall, and other engineering efforts to overcome negative impact of natural disasters and to expand human activities upon potential hazardous areas. However, too much dependent on structural implementation could increase critical damages on properties in hazardous areas when actual events occur. After the 1970s, many hazard scholars have argued that structural implementation and non-structural one should be balanced when local emergency agents consider natural hazard mitigation at a local level and regulate development activity in hazardous area (Berke 1998; Burby, 1998; Burby et al., 2000; Nelson and French, 2002; Zhang, 2010). In addition, scholars have asserted that stand-alone mitigation plan should be integrated with a local comprehensive plan (Deyle and Smith, 1998 and Godschalk et al., 1999). That would be because most disaster losses result from localized natural disasters. Then, many have argued that local comprehensive plan should involve local hazard mitigation plan. Of course, there is the catastrophic disaster such as Hurricane Andrew, Hurricane Katrina, and Great Japan Earthquake, which makes people to pay attention to risk perception and preparedness for the future disasters and also makes governments to retrospect their capability and capacity for natural and man-made disasters. As the above reason, however, we need to more focus on the localized issues such as a LHMP to minimize or mitigate localized disasters. These localized disasters, of course, are not limited to one jurisdiction but transjurisdictions and multiparty issues (Brody, 2003). Yang, et al (2009) found that community businesses to environmental disasters are specifically vulnerable not just only physically such as lifelines, infrastructures but also non-physically, capital mobility, business size, market devastation. Therefore, all efforts to mitigate adverse impacts from natural hazards should set forth at a local level to be resilient communities. In a sense, there should be higher governmental entities to mix this local level of efforts up in order to cope with the characteristics of natural hazards such as trans-boundaries. To do this, it should be starting at a LHMP, which is the very commitment to protect its localities and their properties. From 1960s and through 70 s in the United Sates, many studies have begun to how to evaluate the plan quality (Hill, 1968). Hill studied alternative plans for public investments, particularly water resources development, so that which plans better serve the set of purposes. He also argued that rational planning process is the best way to maximize the expected attainment of a set of given resources, using a traditional cost-benefit analysis by means of the evaluation plans. Ultimately, he compared the plan with an alternative plan for public investment through goals-achievement matrix. However, it is not focusing on the plan quality itself but more likely to a specific project due to the character of cost-benefit analysis whereas Alterman and Hill (1978) studied the relationship between planning and implementation, or plans and their performance through a case study, which compared the outline plan with the detailed plan in a study area by using building permits accordance.

However, it is gradually necessary for plans to be evaluated since disaster damage cost is getting growing. Baer (1997) may be the one who established to harden foundation about plan quality evaluation with indicators and criteria under some categories. He proposed that there were around sixty indicators to assess general plan quality under eight categories and also insisted that plan should be explicitly explained about ideas for a city to aim at, rationality, and readability that plans should be attractively laid out and easy to read by using graphics and maps. Based on Baer's contribution, many empirical and theoretical researches have been conducting. Of those, Berke, Godschalk, and Kaiser (2006) developed a plan quality evaluation protocol on the basis for fact, goal (objective), and action. The protocol devised to grade plans based on scoring either 0 (not identified), 1 (identified, but slightly mentioned and vague), 2 (identified, with detailed information and clear) with indicators under three categories. By doing so, plan quality could be quantified and could be possibly compared with other cities or municipalities not a project-base but whole plan itself. With their efforts, its protocol has been used in many part of planning fields such as ecosystem management (Brody, 2003a), sustainable development (Berke and Conroy, 2000), plan quality associated with natural hazard emergency (Brody, 2003b), planning theories with environmental plan quality (Tang and Brody, 2009), a local plan quality (Berke, Backhurst, Day, Ericksen, Laurian, Crawford, and Dixon, 2008), local environmental planning by evaluating comprehensive plan for each jurisdiction occupied by a significant wetland permit cluster 
(Brody and Highfield, 2005), measuring tsunami planning capacity (Tang, Lindell, Prater, and Brody, 2008), coastal zone land use planning capacity (Tang, 2008), climate change action plan quality (Tang, Brody, Quinn, Chang, and Wei, 2010), and evaluating local land use plans' Environmental Impact Review (Tang, Bright, and Brody, 2008). Actually, there are more than the above such as wild fire plan, landslide plan and so on. Indeed, Berke, Godschalk, and Kaiser (2006) have contributed to the knowledge of plan quality evaluation quality. The next will explain that how the plan be evaluated and what indicators be used for plan quality evaluation.

\section{Research Method}

This plan quality evaluation method, indeed, would not be perfectly credible for a local government's willingness to mitigate potential natural threats in a local. However, it would be a good starting point to make a LHMP, local commitment for a resilient community, strengthen. Indicators that used in this research are total eighteen. The previous researches through literature review found many possible indicators around thirty to sixty in the United States. However, these are mostly planning tools such as setback, subdivision, zoning, or conformity / nonconformity and different political procedure. Some of these are commonly used in other countries but some of them are not in a LHMP. That is why not many indicators used in the research, but the indicators used in the research are fairly fundamental basis to achieve safety against local natural threats.

The study site has mainly faced with flood natural hazard and land slide from Mt. Aso as major threats. Indicators in this research will focus on very common fact, goal, and action such as Socio-economic status (SES), local government commitment to reduce potential losses and preparedness for the future events because of political and cultural differences. However, this protocol would be the best one in longitudinal case study. That is because it is based upon the fact-oriented measure and it can minimize evaluators' subjectivity due to the above reason. Measurements of plan quality were calculated by the sum of score obtained by each indicator analysis in plans. Each indicator under three categories will analyse the extent which the detailed information into a plan was included. It suggested that plans include strong commitment to achieve proposed goals and polices. Therefore, to get higher scores $($ score $=2)$ at a certain indicator, the text into local plan should have a strong willingness to implement policies such as shall, will, or must. The score will be 1 if a willingness to do in local plan to execute policies weaker than the above such as suggested, encourage, or consider. The item or indicator will be scored as 0 if only there is no mentioned at all for that indicator. Finally, the score of indicators will be summed under each category (Fact, Goal, and Action).

$$
\begin{aligned}
& P C_{j}=10 / 2 m_{j} \sum_{i=1}^{m_{j}} I_{i} \\
& T P Q=\sum_{j=1}^{3} P C_{j}
\end{aligned}
$$

Where $P C_{j}=$ quality of the $j$ th plan category (ranging $0-10$ ), $m_{j}=$ number of indicators within the $j$ th plan category, $I_{i}$ represents the $i$ th indicator's score (ranging from 0-2); and $\mathrm{TPQ}=$ total scores of a whole plan (ranging from0-30)

The score will be divided by total possible maximum scores in each category. Total possible maximum scores depend upon the number of indicators. This score will be twenty if a number of indicators are ten under the fact category (Berke, Godschalk, and Kaiser, 2006; Berke and Conroy, 2000). Research team members were consisted of two professors, one researcher, and one graduate student who is the author. Research team members were individually evaluating 2001 and 2011 plans with indicators in Table 1. After done evaluating plans, members met at a table and discussed the individual result so that why certain indicators got certain scores. This was conducted three times to decrease subjective interpretation error when evaluating plans and increase reliability as well. Indicators under each category will be explained in next subsection.

\subsection{Fact}

As seen in the past researches, finding facts in a plan can be a starting point of the research. The stronger factual basis a community has the more sustainable a community can be. Fundamentally, the fact basis components will contain the hazardous location and extent of hazard damage, environmentally sensitive areas, map of hazard magnitude, exposed populations, specifically the children, elderly and disabled, structural loss estimates, evacuation route and clearance time. It would be highly possible that economically vulnerable group and the disabled may be exposed to the natural threats. Furthermore, it is critical that technical skills such as Geographical Information System (GIS) and experienced staff members (man-power) in a local area.

\subsubsection{Population/Population Growth}

Population is the critical factor in hazard mitigation plan. It is fundamental to know exposed population in a hazardous area. Additionally, larger population jurisdiction may have more financial, man-power, and material opportunity to reduce a local hazard. Apparently, it is critical that the population growth 
prediction within a local boundary for the right population cohort. Through this fact finding, a local government will properly set up the goals/objective, and prepare for the local hazardous area as well as for future local hazard mitigation plan and even comprehensive plan.

\subsubsection{Children, the Elderly and Disabled}

Specifically, children and the elderly groups are extremely vulnerable to the natural threats. In Japan, aging society has been started few decades ago. Specifically, the young have rapidly left suburban areas such as a mountainous district, less infrastructural areas, and industrial areas. For instance, there are hundreds people living around Mt. Aso. It can be said that they are all highly exposed to landslide while rapid heavy raining. Two years ago, 23 people died and 2 people missing for the heavy raining. This is, of course, because of rapid heavy raining in a short time. However, a local government should know where the vulnerable groups have mostly resided in. As all know, the above three groups are less movable than other groups. Therefore, it is necessarily to know that how many and in which areas children and the elderly in a local have resided. This can be drawn from population/population growth in a local. With its information, a local government can well recognize where vulnerable population cohorts live and prepare for proper techniques or legal obligations for the dependent. Apparently, a local government can provide proper education programs for the people who take care of the dependent.

\subsubsection{Single-Headed Household}

A single-headed family could have suffered financial difficulties. They may have less time and interest on hazard issues when compared to others simply because they have to work harder to make money. Additionally, they would tend to be less-educated thus they may have less concerned to natural hazard and environmental issue on their community. However, this indicator can be too sensitive to expose to the public, so this sensitive information should be carefully dealt with in LHMP.

\subsubsection{Number of Local Critical Facilities}

It is very important where local critical facilities are located on such as police, fire stations, hospitals, power lines/plant, and water and sewage system. It is highly recommended to check current locations of the critical facilities and their capacities by looking it up in local hazard map so that local governments could precisely prepare for local capacity and alternative plans when hazards would occur. Definitely, this information should be shared with the localite, thus they can get help anytime when need it by local public notice channels.

\subsubsection{Number of Private Structures}

This is to estimate how many private structures are exposed to current local hazard threats as the above. Through it, it can be possible to estimate potential private property loss and predict shelter demands within a local area.

\subsubsection{Median Household Income}

It is important that recognizing local median income level. This is because median household income would be the one to determine the local economy index than national level. High level of community would better prepare for local hazard than that of low level. Local government financial soundness would have positive effect on the local mitigation plan. It could be highly correlated with local education level based on the former researches.

\subsubsection{Households Below Median Income \& Households Below Poverty Line}

This is related to the above indicator. However, it is necessity in order to find out how much population rate is exposed to the vulnerability of threats. Many previous studies found that the financial vulnerability of household is related to other social status, which makes households be exposed to not only economically vulnerability but also physically one as a social component.

\subsubsection{Emergency Plan and Shelter}

An emergency plan used to include clearance time and shelter capacity information on it. It is necessarily that emergency staff member to cope with hazards, emergency shelter demand, and current capacity data. This has also deeply something to do with regular plan updating and local population growth, thus, it makes sure of potential shelter demands and capacities.

\subsection{Goal or Objective}

Goals/objectives evaluate that how much the hazard mitigation plans have a commitment in order for a local to reduce property loss and local fiscal loss, protect localites, private properties, and public facilities in the plan context based on the fact information in a local. A local government, of course, can prepare its vulnerabilities of future frequent local natural hazards in advance. It shall be a long-term, consistent, clear, and effective way to pursue a sustainable development and positive community growth. Thus, it finds out any goal and objective related to flood mitigation at a local level.

\subsubsection{Efforts to Discourage Development Activities} Within Local Hazardous Areas

The best way to reduce hazard impacts is to prevent develop- 
ment activity within hazardous areas at the beginning of development. A local government may have abundant data related to local hazard threat and hazardous area. If a local government and elected official would have a strong and long-term commitment to reduce a local hazard threat, they could prevent development activity at hazardous areas in a local. It makes a solid fiscal income of a local government. With a long term point of view, however, it may help a local government save their extra money to spend huge post-disaster cost by discouraging development activity within hazardous areas.

\subsubsection{Efforts of Property Protection}

It is definitely needed to protect private properties even if a local government would approve developments within a hazardous area. For example, there would be a strong building code for a certain area, high insurance rate, and specific site plan, including environmental impact assessment.

\subsubsection{Efforts to Natural Resources}

In a local hazard mitigation plan or comprehensive plan, there should be some efforts to improve local natural resources such as water resources through stormwater management, environmentally sensitive area, and other local unique resources. This can be viewed as 'give back to the nature'.

\subsubsection{Efforts to Repetitive Fiscal Loss}

Local government revenue is quite limited to local priority businesses. Also, its source of income is too limited to spend all local priority. Therefore, when an emergency happens, it would be a serious problem to a local government thus, there should be some efforts to maintain local fiscal status and ultimately protect local fiscal losses through many administrative activities.

\subsubsection{Efforts to Promote Sustainable Community} (Recreational Area/ Preservation Open Space)

Hazard mitigation efforts have been fundamentally included to the idea of sustainability. Environmentally sensitive area should be given back to the nature. The least structural measurements need to be implemented to a local area. By doing that, many environmental areas can be preserved and these areas turn to be developed as an environment-friendly recreational area for the citizen.

\subsubsection{Efforts to Public Institutional Facility}

Public institution facilities are regarded as the core of local vitality. Of those, a city hall and elementary schools in Japan can be an important factor. It is necessarily that their locations and building code should be checked whether or not it is way enough. Thus, there should be some effort to improve its functions and capacities.

\subsubsection{Efforts to Local Awareness Promoting}

Awareness systems have been identified as the cornerstone in many researches. In practice, there have been good examples to show how important awareness systems are. In the plan, it should be checked that what kinds of effort to improve local awareness systems. Additionally, many technical improvements have been made for the decades such as IT, cell phone, and high speed internet. Therefore, there should be some effort to intermingle the above technologies into current system.

\subsubsection{Efforts to Improve Communication and Coordination}

Specifically, communication and coordination can be divided by two separate sections; administrative and community. It is a critical part that communication between the local governments/ communities and academia/communities. It is well known that natural hazard and environmental issues are not limited to one jurisdiction but trans-boundary. There should be efforts to make it clear to better communicate and effective coordinate among entities on goals and objectives in a LHMP. Explicitly, the communication with the public would be the hot issue on the procedure with a hazard mitigation plan making. Furthermore, the coordination with it should be coped with very carefully. In a LHMP, there should be how to deal with coordination with local governmental entities. One example can be a regular meeting to discuss natural hazard issue between adjacent local governments.

\subsection{Implementation or Action}

This part will be the most important one of three categories to evaluate a plan context because any effort of goals and objectives could be useless if there would be no clear check-up system, time schedule for a certain implementation commitment, feasible financial and necessary technical support. It will include what actions/implementations are associated with reducing housing or public institutional facilities damage, and recovery efforts, and then increasing emergency awareness, alert systems, and public participation, then incentives.

\subsubsection{Check-Up System}

This is one of monitoring systems. For example, one city sets up the goal to protect riverside housings from flood event. The city would plan many possible alternatives within city's feasible fiscal status. There should be proper checkup systems so that public officials should check that those projects are well 
processing as they are expecting. This check-up system will include who, when, where information so that feedbacks from the meeting will be a virtuous circle.

\subsubsection{Proper Time-Schedule}

Every project to protect lives and properties should have a fine time-schedule. This would be very common-sense if the mitigation plan would be a project-based. Currently, the KCRHPP is, however, not a project-based plan. For that reason, it would be hard to find proper time-schedules for a certain project into the KCRHPP. Unfortunately, there is any mention about projects on the purpose of getting rid of hazard danger. Possibly, this issue may be coped with not in emergency department, but in architecture and civil department. However, it is strongly recommended that the time-schedule for a certain project, which can be community's goal and objective, be open to the public to know infrastructure improvements. It would be highly possible that the information can be scattered into other plans. However, the above information should be combined into one plan such as LHMP, emergency plan, or comprehensive plan.

\subsubsection{Public Participation Skill}

It can be involved to communication and coordination categories. However, the coordination category in some countries, Japan or Korea, Republic of, cannot be the same one with the U.S., which is three different governmental entities (Federal, States, and local government). On one hand, they have to intimately coordinate with governmental entities to make a better result not only in the urban planning issue but also in the other issues. On the other hand, clearly communicating one another would be difficult due to systematic hierarchy and, of course, take more time to proceed a task given. Communication may be easier than the United States in Japan. As we all know, it would be because Japan is simpler hierarchy. Nevertheless, communication \& coordination category should be also treated as a high priority in Japan. The localite knows local problems such as geographical features, and chronic local natural threats more than any organizations. Therefore, the plan includes how much the localite get involved when the implementations/ actions have been enacted and it should identify the relationship between a local government and the public, including stakeholders. Therefore, it is extremely important that which participation skills be applied in order to boost the citizen participation on a local hazard mitigation plan procedure. Therefore, it is necessarily whether or not there are ordinances that localites can actively take part in a planning procedure.

\section{The result of KCRHPP Evaluation}

Based on the previous researches, our team assessed the Kumamoto City Regional Hazard Prevention Plan (KCRHPP) with own indicators. Our team has expected large differences between two plans simply because of 11-year time period.

Meanwhile, In spite of repetitive flood events on specific areas, it was hard for us to find the detailed map for those areas and information about the citizen in who have been lived. However, our team at least could find the addresses of potential dangerous areas and spots, possibly affected by future floods and landslides in 2012 KCRHPP. It has been improved in fact plan category compared to 2001 KCRHPP. As mentioned the above, it is because 2012 KCRHPP has more detail information for the potential hazardous areas. For example, there are specific building names, underground areas in downtown and addresses, but unfortunately no maps for it. The following is the descriptive analysis for the plans.

\subsection{Fact}

In 2001 plan, some indicators could not be found when it had been evaluated. In this case, a score of 0 was assigned to those missing indicators. For instance, the number and location of single head of household, number and location of local critical facilities, number of private structures exposed to natural hazards, median household income in Kumamoto City, the number of household with income below median income and households below poverty. It would be possible that some indicators cannot be open to the public such as household below poverty and single head household. Even though their exact address cannot be on the plan, the local government should recognize how many, where they are and finally, specific plan for them. When it comes to Socio-Economic Status (SES), specifically in a hazard mitigation plan, it is concerned that those are very important indicators that those citizens will be easily exposed to threats when the events would occur. Apparently, they do not have many opportunities to get proper information in right time and right place. However, we cannot check if

Table 2. The descriptive score for KCRHPP between 2001 and 2012

\begin{tabular}{c|c|c|c|c}
\hline & Fact & Goal & Action & TPQ \\
\hline 2012 KCRHPP & $\mathbf{5 . 3 2} / 10$ & $\mathbf{5 . 3 2} / 10$ & $\mathbf{0 . 8 4} / 10$ & $\mathbf{1 1 . 4 8} / 30$ \\
\hline 2001 KCRHPP & $\mathbf{3 . 7 6} / 10$ & $\mathbf{5 . 6 3} / 10$ & $\mathbf{1 . 6 7} / 10$ & $\mathbf{1 1 . 0 6} / 30$ \\
\hline
\end{tabular}


Kumamoto city has information or not in another part of plan. At least, the information has not been included in both plans.

On the other hand, some parts were well explained in both plans. In the beginning of the plans, it has showed the trend of population growth and the geographic feature of Kumamoto city. In addition, both plans have had relatively detailed progresses and procedures for the vulnerable dependent such as children, the elderly, and the disable. However, there was unfortunately not more detail information for the dependent. It was too vague to follow city's evacuation plan or to take them out of hazardous places.

\subsection{Goal}

This component has been slightly decreased during research period. Basically, we do not think it does mean that the effort of city to decrease natural hazard damage in the city is decreasing. There are many other efforts and goal to mitigate flood hazard in the city out of our goal/ objective plan component. Unfortunately, there were few efforts and goals within our indicators. It was hard to find indicators such as 'effort to discourage development activity within local hazardous area', 'any efforts of property protection', and 'any effort to public institution facility'. These efforts are initially contributed to minimize the possibility of natural hazard loss in a local. Unfortunately, development activities in hazardous areas are still prevailing. There would be many reasonable causes such as lack of land, strong building codes, or weighted insurance policy. However, any of those could not be found in the plan. Additionally, the plan is simply mentioned that where potentially private properties exposed to natural hazard are. In Japan, elementary school district is the least unit that citizen could evacuate. Local elementary schools are the shelter for the citizen if hazards would occur. Based on the evacuation plan and route, the localite should keep in mind where the closest elementary school is and they would evacuate to it when the event happens. Therefore, 'any effort to public institution facility' could be one of the critical goals in the LHMP. Also, the local government has to try its best let its citizens know where shelters are and maintain those facilities. There is a very strong goal; 'effort to improve communication and cooperation between jurisdictions'. As known by many researches, extremely severe natural hazards or man-made hazards are never limited by one jurisdiction, but trans-boundary. Therefore, it is highly significant that adjacent jurisdictions have to have better communication channels, regulations, and plans to help one another. In this aspect, the KCRHPP has had a good quality of communication and cooperation level among adjacent jurisdictions.

Actually, a large amount of the plans are assigned in this sec- tion, Goal and Objective. However, much information are scattered in the plan. It should be combined so that local officials could easily maintain broad goals and detail objectives and, of course, efficiently deal with implementation/ action.

\subsection{Implementation, Action, and Monitoring}

This component has the least indicators in this evaluation, proper check-up system (monitoring), precise time-schedule for a certain implementation/policy, and citizen participation. However, all of them are very important factors. In spite of importance, there are only three indicators because it has taken into account for cultural differences when compared with the Northern American literatures.

Even though this component is extremely important to cope with natural hazard damage in a local level, it has been expected that this component would be little weak rather than other components. In the KCRHPP, it is very hard to find action plan, monitoring system or implementation for a local governmental commitment to the proposed policies. Interestingly, as shown in Table 2, the scores are exceptionally low in both two plans ( 0.84 and 1.67 out of 10 , respectively). Even if our team expected low points for this section, the result is extremely lower than expected. Moreover, the score in 2012 plan is significantly decreased, compared to the 2001 plan. There could be one possible explanation for it; differences in interpretations for indicators among evaluators. Fundamentally, it can be said that there is not much monitoring systems for implementation and action in KCRHPP based on our research. It could not be a proper expression that which component would be more important than others when a LHMP is assessed. Nevertheless, it can be said that this component has played a pivotal role in monitoring/managing local governmental commitment to make resilient communities for a certain natural hazard. Importantly, there is no section for citizen participation during the LHMP making process. In many other countries, public hearings and other types of input are regularly held to bring local community efforts. Unfortunately, there is any ordinance to hold regular citizen participation to improve the better quality of LHMP in KCRHPP. In addition, it was basically hard to find local government improvement plan for the repetitive flood areas. Accordingly, precise time-schedule for a certain implementation/policy cannot be found in both plans.

\section{Conclusion and Recommendation}

This is a time-consuming research because whole plan should be scrutinized several times. However, it is strongly 
believed that plan evaluation for a local community should be regularly conducted to know if a Local Hazard Mitigation Plan (LHMP) is strong enough to protect the localite and their properties. As shown by Table 2, Total Plan Quality (TPQ) in KCRHPP is slightly improved during the study period (11.48 and 11.06 in 2012 and 2001, respectively). This is a surprising result to our research team because it cannot be said that there is no improvement at all when it comes to LHMP during 11year study period. Furthermore, TPQ scores are awfully low rather than we expected. It has basically resulted from extraordinarily low score of Implementation/ Action plan component. In contrast, there is relatively good improvement from 3.76 to 5.32 in the fact plan component. However, fact component should be more enhanced because this is the starting point to make communities resilient. If some information could not be written on the plan due to the personal information protection law, relevant information should be easily found when it is necessarily. To do so, it is, again, highly needed that high level of communication and cooperation between relevant departments, not just emergency department. Then, local government could well take care of the dependent such as the elderly, children, the disable, and socially minorities not only daily life but also emergency.

There are four recommendations through this research; detail, project-oriented, maps, integrating natural hazard plan (standalone plan) into local comprehensive plan.

First, the KCRHPP is huge amount of document and very systematic but not detail for a certain point. Even though we have focused on only flood event in this research, it actually covers other natural hazards and man-made hazards. That would be good for locals but LHMP should be more detail, not vague.

Second, the KCRHPP should be project-oriented plan. As seen in Implementation/Action plan component, it does not include any kind of implementation/ action to the future hazard mitigation project. That is the reason there was no time-schedule for a certain project at all. If the KCRHPP would be more project-oriented plan, local officials could find some necessary data or information at one time. It would make working efficiency for local officials to be high enough.

Third, it does need maps in the plan. There is only map for a geographic purpose in the KCRHPP. However, it is absolutely needed to get more information through maps such as local land use, 100-year floodplain, and repetitive flooded area map, which is exposure to the public. Even if a local government would have stand-alone plan for each hazards, each plan should have land use plan for the future hazards so that local officials would recommend policy makers and elected officials to change positively future local development plan. Furthermore, 100-year floodplain map would make positively effect on evacuation time, potential economic loss, and housing choice pattern. Of course, there is the map, called 'Hazard Map'. However, it is not currently included into the KCRHPP but disperse to the public. One thing concerned about is that this map covers too many information and colors on small one page paper. This type of map could possibly make people confuse when real event occurs. Therefore, there should be solid improvement for the hazard map. For example, it does not need to fill up all information on the map, but 100-year floodplain, 500-year floodplain and shelters. Also, we propose the local government to make an independent evacuation route map based on elementary school district, which is called Machi in Japan, so that the localite would easily read the map and current hazard map would be simpler.

Last, in order to make it all possible, a local government should integrate stand-alone hazard plan into the local comprehensive plan. We do not argue that stand-alone plan is not good enough to deal with local natural hazards. It is definitely needed in some places such as nuclear power plan, strong wind hazard, and potential tsunami. However, a local comprehensive plan covers all from current to future community growth management. Therefore, many hazardous areas can be ruled out when the plan would establish. It would be very effective and efficient because relevant people would get together to share ideas and plan such as local planners, emergency managers, fire chief, police, local economic official. This research is initially done by using other scholars' contribution for the evaluation of community of Northern America. Therefore, further studies are needed to develop more appropriate and detailed indicators in all plan components associated with Japan culturebased or it would be called 'the eastern culture-based' (politically and socially). This research is around 10-year time period to compare one city's natural hazard mitigation plan capability in order to better understand the city's performance to mitigate a major natural threat. However, it does, of course, need more samples to compare with region by region to get statistical significance. Unfortunately, however, LHMPs in Japan are mostly homogenous unlike communities of the United States or European cities. Therefore, further study should be conducted due to the fact that LHMPs comparison of communities in Japan is not possible because they are basically homogeneous. Further research about the contrast of suggested LHMP best practice based on successful approach used in developed (the United States and Japan) and developing country, which may be Korea, with appropriate support would be necessary to understand what aspects would different with the developed countries and which should be improved based on comparison case study. 
Ultimately, this would make the citizens improve self-preparedness and risk perception for the future potential loss. Finally, it makes a virtuous cycle in the local community to be resilient community for natural hazards.

\section{References}

Alterman, R. and Hill, M. (1978) Implementation of Urban Land Use Plans. Journal of the American Institute of Planners, Vol. 44, No. 3, pp. 274-285.

Amao, Y., Yamazaki, Y., and Takaki, A. (2007) A Gap between Disaster Preparedness and Awareness about Flood Risk. Journal of Japan Civil Engineering, 24, 299-306.

Baer, W.C. (1997) General plan evaluation criteria: An approach to making better plans. Journal of the American Planning Association, Vol. 63, No. 3, pp. 329-344.

Berke, P. (1998) State growth management and natural hazard risk reduction. Journal of the American Planning Association, Vol. 64, No. 1, pp. 76-87.

Berke, P.R., Backhurst, M., Day, M., Ericksen, N., Laurian, L., Crawford, J., and Dixon, J. (2006) What makes plan implementation successful? An evaluation of local plans and implementation practices in New Zealand. Environment and Planning B: Planning and Design 33, pp. 581-600.

Berke, P.R. and Conroy, M.M. (2000) Are we planning for sustainable development? An evaluation of 30 comprehensive plans. Journal of the American Planning Association, Vol. 66, No. 1, pp. 21-33.

Berke, P.R., Godschalk, D.R., and Kaiser, E.J. (2006) Urban Land Use Planning $\left(5^{\text {th }} \mathrm{ed}\right.$.). Urbana and Chicago: University of Illinois Press.

Brody, S.D. (2003) Measuring the effects of Stakeholder Participation on the Quality of Local Plans Based on the Principles of Collaborative Ecosystem Management. Journal of Planning Education and Research 22, pp. 407-419.

Brody, S.D. (2003a) Implementing the principles of ecosystem management through local land use planning. Population and Environment, Vol. 24, No. 6, pp. 511-540.

Brody, S.D. (2003b) Are we learning to make better plans? A longitudinal analysis of plan quality associated with natural hazards. Journal of Planning Education and Research., Vol. 23, pp. 191-201.

Brody, S.D. (2003b) Are we learning to make better plans? A longitudinal analysis of plan quality associated with natural hazards. Journal of Planning Education and Research, Vol. 23, pp. 191-201.

Burby, R.J. (1998) Cooperation with nature; Confronting natural hazards with land use planning for sustainable communities. Washington, DC: Joseph Henry Press.

Burby, R.J., Deyle R.E., Godschalk, D.R., Olshansky, R.B. (2000). Creating hazard resilient community through land-use planning. Natural Hazards Review 1, Vol. 2, pp. 99-106.

Deyle, R. E., and Smith, R. A. (1998). Local government compliance with state plannig mandates: The effects of state implementation in Florida. Journal of the American Planning Association, Vol. 64, No. 4, pp. 457-469.
Godschalk, D.R., Beatly, T., Berke, P., Brower, D.J., and Kaiser, E. J. (1999). Natural hazard mitigation: Recasting disaster policy and planning. Washington, DC: Island Press.

Hill, M. (1968) A Goals-Achievement Matrix for Evaluating Alternative Plans. Journal of the American Institute of Planners, Vol. 34, No. 1, pp. 19-29.

Tang, Z. (2008) Evaluating local coastal zone land use planning capacities in California. Ocean \& Coastal Management, Vol. 51, pp. 544-555.

Tang, Z., Bright, E., and Brody, S.D. (2008) Evaluating California local land use plan's enviornmental impact reports. Environmental Imapct Assessment Review, Vol. 29, pp. 96-106.

Tang, Z. and Brody, S.D. (2009) Linking Planning Theories with Factors Influencing Local Environmental Plan Quality. Environmental and Planning B: Planning and Design, Vol. 36, pp. 522-537.

Tang, Z., Brody, S.D., Quinn, C.E., Chang, L., and Wei, T. (2010) Moving from agenda to action: Evaluation local climate change action plans. Journal of Environmental Planning and Management, Vol. 53, No. 1, pp. 41-62.

Tang, Z. Lindell, M.K., Prater, C.S., and Brody, S.D. (2008) Measuring Tsunami Planning Capacity on U.S. Natural Hazards Review, Vol. 9, No. 2, pp. 91-100.

Okada, N., Na, J., and Fang, L. (2013a) The Yonmenkaigi System Method: An Implementation-Oriented Group Decision Support Approach. Journal of Group Decision and Negotiation, Vol. 22, pp. 53-67.

Okada, N., Fang, L., and Kilgour, D.M. (2013b) Communitybased Decision Making in Japan. Journal of Group Decision and Negotiation, Vol. 22, pp. 45-52.

JSCE. (2013) Inspection report for heavy raining and flood in Northern Kyushu, July 2012. Japan Society of Civil Engineering, Western Branch in Kyushu.

Matsuda, Y. and Okada, N. (2006) Community diagonosis for sustainable disaster preparedness. Journal of Natural Disaster Science, Vol. 28, No. 1, pp. 25-33.

Nelson, A.C. and French, S.P. (2002) Plan quality and mitigating samage from natural disasters: A case study of the Northridge earthquake with planning policy considerations. Journal of the American Planning Association, Vol. 68, No. 2, pp. 194-207.

Yamada, F., Kakimoto, R., Yamamoto, M., Fujimi, T., and Tanaka, N. (2011) Implementation of community flood risk communication in Kumamoto, Japan. Journal of Advanced Transportation, Vol. 45, pp. 117-128.

Yamazaki, Y., Amao, Y., and Takaki, A. (2008) A Study on Preparedness for Flood Disaster and Promotion Measures. Journal of Japan Civil Engineering, Vol. 25, No. 1, pp. 85-92.

Zhang, Y. (2009) Vulnerability of community businesses to enviornmental disasters. Disaster, Vol. 33(I), pp. 39-57.

Zhang, Y. (2010) Residential Housing Choice in a Multihazard Environment: Implaciations for Natural Hazardds Mitigation and Community Environmental Justice. Journal of Planning Education and Research, Vol. 30, No. 2, pp. 117-131.

\begin{tabular}{|l|l|}
\hline Received & May 20, 2014 \\
\hline Revised & May 28, 2014 \\
\hline Accepted & August 21, 2014
\end{tabular}

